\title{
Weight Misperceptions and Racial and Ethnic Disparities in Adolescent Female Body Mass Index
}

\author{
Ramona C. Krauss, ${ }^{1}$ Lisa M. Powell, ${ }^{2}$ and Roy Wada ${ }^{2}$ \\ ${ }^{1}$ Department of Economics, University of Illinois at Chicago, Chicago, IL 60607, USA \\ ${ }^{2}$ Institute for Health Research and Policy, University of Illinois at Chicago, Chicago, IL 60608, USA
}

Correspondence should be addressed to Lisa M. Powell, powelll@uic.edu

Received 2 December 2011; Revised 6 February 2012; Accepted 17 February 2012

Academic Editor: Simone Lemieux

Copyright (C) 2012 Ramona C. Krauss et al. This is an open access article distributed under the Creative Commons Attribution License, which permits unrestricted use, distribution, and reproduction in any medium, provided the original work is properly cited.

\begin{abstract}
This paper investigated weight misperceptions as determinants of racial/ethnic disparities in body mass index (BMI) among adolescent females using data from the National Survey of Youth 1997. Compared to their white counterparts, higher proportions of black and Hispanic adolescent females underperceived their weight status; that is, they misperceived themselves to have lower weight status compared to their clinically defined weight status. Compared to their black counterparts, higher proportions of white and Hispanic adolescent females misperceived themselves to be heavier than their clinical weight status. Oaxaca-Blinder decomposition analysis showed that accounting for weight misperceptions, in addition to individual and contextual factors, increased the total explained portion of the black-white female BMI gap from $44.7 \%$ to $54.3 \%$ but only slightly increased the total explained portion of the Hispanic-white gap from $62.8 \%$ to $63.1 \%$. Weight misperceptions explained $13.0 \%$ of the black-white female BMI gap and 3.3\% of the Hispanic-white female BMI gap. The regression estimates showed that weight underperceptions were important determinants of adolescent female BMI, particularly among black and Hispanic adolescents. Education regarding identification and interpretation of weight status may play an important role to help reduce the incidence and racial disparity of female adolescent obesity.
\end{abstract}

\section{Introduction}

The prevalence of obesity has reached epidemic proportions in the past few decades. Among adult females, disparities in obesity rates exist between non-Hispanic white women compared with both non-Hispanic black and Hispanic women whose respective obesity prevalence rates were $33.0 \%, 49.6 \%$, and $43.0 \%$ in 2007-2008 [1]. The data show that these disparities are already present in adolescence. In fact, the current racial/ethnic obesity disparity among adolescent girls is striking with the prevalence rate for non-Hispanic black girls of $29.2 \%$ being more than twice the rate for nonHispanic white girls of $14.5 \%$ [2]. Hispanic female youths are also heavier than their non-Hispanic white counterparts with an obesity prevalence rate of $17.5 \%$, which is $21 \%$ higher than the rate among white female youths. The existing weight disparities at adolescence are of concern and suggest that future disparities may grow even further given that obesity tracks into adulthood [3]. It is important to understand the underlying factors that contribute to these disparities because obesity is associated with a series of negative health outcomes such as diabetes, heart disease, and cancer, and labor market outcomes related to wages and income [4-6].

A number of previous studies tried to explain the racial/ethnic disparities in adolescent weight outcomes by examining racial/ethnic differences in household socioeconomic status (SES) and differences in economic and environmental contexts. The relationship between obesity and SES was found to be complex, and it varied by race/ethnicity. For example, Gordon-Larsen et al. (2003) found an inverse relationship between overweight prevalence and SES for white adolescent females but overweight prevalence did not decrease with increased SES for either black or Hispanic teen girls. Using simulation analyses, the study showed that the racial/ethnic variation in overweight remained even when adolescents had similar SES, which suggests that other factors 
beside SES might be responsible for the weight disparities [7]. Consistent with Gordon-Larsen et al. (2003) findings, Wang and Zhang (2006) found a negative relationship between SES and weight for white teens, but no clear relationship was found for black teens [8]. A recent study that examined parental SES along with economic contextual variables found that these factors altogether explained a large portion of the racial/ethnic weight gap for adolescent males but not for females and, in particular, explained the least amount (only 44\%) of the racial gap in body mass index (BMI) between black and white adolescent females [9].

Previous studies did not directly account for the importance of social and cultural differences in weight perceptions as potential contributors to racial/ethnic disparities in weight outcomes. Weight misperception, the discrepancy between individual perceptions of weight status and actual weight status based on clinical definitions of weight, is believed to be an important factor in the development of obesity, given that the rising prevalence of obesity was paralleled by a higher incidence of weight misperceptions $[10,11]$. Studies showed that between 1988-1994 and 1999-2004 there was an increase in weight misperceptions, particularly among overweight and obese individuals who were more likely to misperceive their weight as clinically normal or healthy $[10,11]$. Evidence shows that the inability to correctly diagnose one's clinical weight status as overweight is strongly associated with the increased risk for obesity [10, 12-15]. These findings could play an important role in explaining the higher incidence of obesity among minorities, as well as the overall trends in obesity prevalence $[14,15]$.

Evidence suggests that there are important racial/ethnic differences in weight perceptions. These differences are related to how permissive one's social and cultural norms are towards excessive weight gain, with black and Hispanic norms concerning weight and weight gain being more permissive than the corresponding white norms [16-18]. A number of recent studies reported that weight misperceptions were more pronounced among black and Hispanic youths who were more likely to underestimate or underperceive their clinical weight status [19-21].

There is a large body of literature investigating racial/ethnic differences in weight perceptions. It was recognized that the predominant Western white culture emphasizes the importance of physical appearance for female success and life satisfaction, with the ultrathin female body being attainable and ideal [22-24]. The sociocultural theoretical model proposed by Stice [22] suggested that racial/ethnic groups with non-Western cultures of origin may not internalize the ultrathin ideal body image embraced by the Western culture and may not place as much value on physical appearance as a means for female success and life satisfaction. As a result, individuals belonging to nonwhite groups may have different weight perceptions when compared to their white counterparts [23-25].

Cultural group attitudes towards weight may influence individual weight status perception through body weight satisfaction, perceived desirability, and perceived attractiveness. There is evidence of racial/ethnic differences in the perception of attractiveness and romantic desirability as a function of body size, with blacks and Hispanics preferring larger body sizes than whites $[16,17,26]$. Barroso and colleagues [16] reported that black and Hispanic adolescent males perceived heavier girls as more desirable than their thinner counterparts. Lower social stigma was associated with being overweight among blacks, with black males also reporting much less stigma than white males when thinking about dating a heavy female [17]. Research indicates that in describing beauty and attractiveness, female black teens placed less emphasis on physical characteristics and more emphasis on psychological traits, whereas white teens were more likely to associate beauty with thinness and were more likely to believe that thinness enhanced their romantic appeal $[15,18,27-29]$. In addition, black women and teens reported substantially higher levels of body shape and size satisfaction compared to their white and Hispanic counterparts [30-33].

The observed racial/ethnic differences in body satisfaction can be partially explained by differences in body ideals, with black and Hispanic youths having heavier body ideals than whites $[16,34]$. Rucker and Cash (1992) found that in a sample of 104 black and white college student females there was no racial/ethnic difference in the perception of own weight. However, they found racial/ethnic differences in body size ideals, with black youths preferring larger body size as ideals than whites [35]. Fitzgibbon et al. (2000) examined differences between body image and body ideals and found that body dissatisfaction occurred at lower BMI levels for white women when compared with their black and Hispanic counterparts [36]. White women reported dissatisfaction at BMI levels corresponding to clinically normal weight, whereas black and Hispanic women did not report body dissatisfaction until they were almost clinically obese. Kronenfeld and colleagues (2010) also found that black women chose smaller silhouettes to represent their current size than their white counterparts, and they reported a preference toward larger silhouettes when compared to the ideal silhouettes preferred by white women [34].

This paper contributes to the existing literature by examining the importance of weight misperceptions as a contributor to racial/ethnic weight disparities among adolescent females. We use a decomposition method to assess the importance of weight misperceptions in addition to differences in individual, parental, and contextual factors. Specifically, our study examines whether weight misperceptions are important determinants of BMI for adolescent females and the extent to which racial/ethnic differences in weight misperceptions explain part of the racial/ethnic disparities in BMI for adolescent females.

\section{Data}

This paper used individual-level data from the National Longitudinal Survey of Youth 1997 (NLSY97). The NLSY97 is administered in the USA by the Bureau of Labor Statistics and follows annually a representative cohort of youths who were aged 12-17 in the first year of the survey, 1997. It contains a large body of information on SES and individual characteristics. This paper used the first four waves of the survey (1997-2000). Our initial sample consisted of 
8,822 person-year observations on an unbalanced panel of 3,378 nonpregnant female adolescents who were living at home and were 18 years of age or younger. In order to be able to match our price data to the NLSY97 data, we restricted our sample to female adolescents who lived in the same or contiguous counties for which price matches were available. This reduced our sample to 5,904 personyear observations on an unbalanced panel of 2,615 female adolescents. Finally, the estimation sample was restricted to include only observations with nonmissing information on all of the covariates examined in the study. Our final estimation sample included 5,035 person-year observations on an unbalanced panel of 2,134 female adolescents living in 312 different counties across the USA This study was approved by the Institutional Review Board of the University of Illinois at Chicago.

2.1. Outcome Measures. The outcomes of interest were the ethnic disparities in BMI between non-Hispanic black (hereafter referred to as black) and non-Hispanic white (hereafter referred to as white) adolescent females (black-white) and between Hispanic and white adolescent females (Hispanicwhite). BMI was calculated as weight (in kilograms) divided by height squared (in meters) using self-reported weight and height collected in each year of the survey.

2.2. Weight Misperception Measure. Indicators for weight misperceptions were constructed as the difference between the survey respondents' perception of their weight status and their actual weight status based on clinical definitions of weight. Each wave of the survey contained a question that asks "How would you describe your weight?" The response to this question was used to create four perceived weight categories: perceived underweight (equaled 1 if "very underweight" or "slightly underweight," 0 otherwise), perceived normal (equaled 1 if "about normal," 0 otherwise), perceived overweight (equaled 1 if "slightly overweight," 0 otherwise), and perceived obese (equaled 1 if "very overweight," 0 otherwise). Each survey respondent was also classified into one of the four weight categories as defined by the Center for Disease Control and Prevention (CDC) age and gender specific growth charts (underweight if BMI percentile $<5$ th percentile; normal weight if 5 th percentile $\leq$ BMI percentile $<85$ th percentile; overweight if 85 th percentile $\leq$ BMI percentile $<95$ th percentile; obese if BMI percentile $\geq 95$ th percentile). Three categorical variables for the correctness of clinical weight perceptions were then created as the difference between individuals' perceived weight and their clinical weight category: overperceived weight status, correctly perceived weight status, and underperceived weight status. An individual was defined as having overperceived (underperceived) weight status if she perceived her weight status as being heavier (lighter) than her clinical weight category. In other words, individuals with underperceived weight status misperceived themselves to be "thinner" or "skinnier" than their actual clinical weight status whereas the opposite was true for individuals with overperceived weight status.
2.3. Controls Measures. We controlled for standard individual and household characteristics including age, age of menarche, youth's income (including allowance and wages), hours per week worked by youth, living arrangements (living with both or just one parent), and mother's working status (working full-, part-time, or not working), which were obtained from the youth reports. We also controlled for parental income and mothers' education as proxies for household SES. Information on parental income (including wages and salary, investments, child support, and social assistance), in each wave, was collected from the parental questionnaire, and data regarding mother's education (less than high school, high school, some college and more) was obtained from both the parental questionnaire and the youth reports.

In addition, we controlled for a number of contextual factors that may contribute to weight disparities. We included measures of fast food prices and food at home prices obtained from the American Chamber of Commerce Researchers Association (ACCRA). These price data were matched to each wave of the NLSY97 sample based on the closest city match available in the ACCRA data using the county-level geocode identifier. Only observations for which price matches from the same or contiguous county were available were included in our analyses. An additional categorical indicator that controlled for prices matched on the same versus contiguous county was added to all the analyses. We also controlled for the commercial food and activity environment using outlet density measures of available food stores (supermarkets/grocery stores and convenience stores), restaurants (fast food restaurants and full-service restaurants), and commercial physical activityrelated outlets obtained from business lists created by Dun \& Bradstreet $(D \& B)$. The outlet density measures were matched by county and year and were defined as the number of outlets per 10,000 capita. The price and outlet measures are described in greater detail elsewhere [37]. Finally, we also controlled for median county-level household income and for the type of residence: urban, suburban, or rural, based on Census 2000 data merged to the NLSY97 by the county-level geocode identifiers.

\section{Empirical Models}

A standard Oaxaca-Blinder decomposition analysis [38, 39] was performed to determine the extent to which weight misperceptions explained the racial/ethnic BMI gaps among adolescent females. This methodology decomposes the observed racial/ethnic disparities in BMI into two main components: explained and unexplained portions. The explained portion is calculated as the interaction between the racial/ethnic differences in the endowments of explanatory factors and the average estimated effects. The explained portion is therefore of main interest because it measures how much of the racial/ethnic difference in BMI can be "explained" in terms of the differential endowments of explanatory factors. The unexplained portion is calculated as the interaction between the population endowments and the weighted average of estimated coefficients by race/ethnicity 
and therefore can be interpreted as the differential response to the determinants of BMI by each racial/ethnic group. To avoid a well-known index number problem associated with Oaxaca-Blinder decomposition, we implement a widely used alternative proposed by Neumark [40], which uses the estimated coefficients from the pooled regression as the average estimated effects. Several recent studies applied this methodology to studying disparities in public health including gender differences in smoking [41], cross-country differences in obesity between the USA and Canada [42] and Spain and Italy [43], and racial/ethnic differences in BMI between black-white and Hispanic-white adolescents [9]. In addition to the results from the decomposition analysis, we present results from the pooled cross-sectional ordinary least squares (OLS) analyses by racial and ethnic subgroups. The standard errors are robust and two-way clustered at the individual and county level [44].

Our two main hypotheses are that (1) weight misperceptions are important determinants of BMI for adolescent females, and (2) racial/ethnic differences in weight misperceptions explain part of the racial/ethnic BMI gap for adolescent females previously unexplained by standard control measures. A substantial increase in the explained portion due to racial/ethnic differences in weight misperceptions would indicate that policies that reduce the racial/ethnic differences in weight misperceptions may help reduce racial/ethnic differences in health outcomes.

\section{Results}

4.1. Descriptive Statistics. Table 1 shows the summary statistics by race/ethnicity for BMI, weight misperceptions, individual and household characteristics, parental SES, and economic contextual factors. On average, white adolescent females had lower BMI by 2.2 units and 0.9 units compared to their black and Hispanic counterparts, respectively. These differences are equivalent to $13.2 \mathrm{lbs}$ and $5.4 \mathrm{lbs}$ difference, respectively, for an average 15-year-old female with a height of $5^{\prime} 5^{\prime \prime}$.

On average, compared to white adolescent females, black adolescents were more than twice as likely to underperceive their clinical weight status, perceiving that they were lighter than they actually were and Hispanic adolescents were almost one quarter more likely to do so $(12.9 \%$ for whites versus $28.6 \%$ for blacks and $15.9 \%$ for Hispanics). Compared to black adolescents, white and Hispanic adolescent females were more likely to overperceive their clinical weight status thinking that they were heavier than they were $(14.1 \%$ for blacks versus $24.9 \%$ for whites and $22.3 \%$ for Hispanic adolescents). The majority of all female adolescents, though to a lesser extent for blacks, correctly perceived their weight status (57.3\% for blacks versus $62.2 \%$ for whites and $61.8 \%$ for Hispanic adolescents).

4.2. Weight Misperceptions by Weight Categories. Table 2 presents descriptive statistics of the weight misperceptions by actual clinical weight categories across the three racial/ethnic groups. Except for the overweight adolescents who correctly identified their personal weight status category, there were no other statistically significant differences between white and Hispanic adolescent girls. In contrast, statistically significant differences between black and white adolescent girls were found for all weight status categories, except for the clinically underweight adolescents and the overweight adolescents who overperceived their weight. For all weight status categories, white adolescents were, on average, less likely to underperceive their actual weight status than their black counterparts. In particular, $15.0 \%$ of overweight white adolescents underperceived their weight status compared to $44.9 \%$ of overweight black female adolescents and 59.0\% of obese white adolescents underperceived their weight compared to $72.7 \%$ of obese black female adolescents.

4.3. Decomposition Results. The contribution of weight misperceptions to the "explained" part of the racial/ethnic BMI gaps is shown in Table 3. The base model (Model 1) included the standard individual and household characteristics as well as economic contextual variables. Model 2 added the weight misperception covariates to Model 1.

The base model, Model 1, explained $44.7 \%$ of the blackwhite disparity in adolescent female BMI (column 1) and $62.8 \%$ of the Hispanic-white disparity in BMI (column 4). Adding the weight misperception covariates in Model 2 raised the total explained portion of the black-white BMI disparity to $54.3 \%$ (column 2) but dropped the portion attributable to individual and environmental contextual characteristics from $44.7 \%$ in Model 1 to $41.3 \%$ in Model 2 . This result suggests that the explanatory power previously assigned to individual and economic contextual factors was in part due to racial differences in weight misperceptions. When the weight misperception covariates were added, the total explained portion of the BMI disparity for Hispanicwhite females remained almost unchanged increasing from $62.8 \%$ to $63.1 \%$. As shown in Table 3, weight misperceptions explained only $3.3 \%$ of the Hispanic-white BMI gap in Model 2. These results suggest that weight misperceptions previously omitted in Model 1 were important and independent determinants of the black-white racial disparity in BMI but less important for the Hispanic-white ethnic disparity in BMI: the portion attributable to weight misperceptions was about $13.0 \%$ for the black-white gap compared to 3.3\% for the Hispanic-white BMI gap. Weight misperceptions therefore contributed significantly to the total explained portion of the black-white BMI gap making up $23.9 \%$ of the total explained portion $(13.0 \%$ of the total $54.3 \%$ total explained) but contributed only modestly to the Hispanicwhite total explained BMI gap, making up only $5.2 \%$ of Hispanic-white total explained portion (3.3\% of the total $63.1 \%$ explained).

4.4. Regression Results. To further understand the contribution of weight perceptions to BMI across race/ethnicity, Table 4 shows the results for the pooled cross-sectional OLS results of the determinants of BMI. The excluded category for weight misperceptions was the correctly perceived weight 
TABLE 1: Summary statistics: means (SD) and frequencies.

\begin{tabular}{|c|c|c|c|}
\hline & $\begin{array}{c}\text { White } \\
N=2,697\end{array}$ & $\begin{array}{c}\text { Black } \\
N=1,316\end{array}$ & $\begin{array}{c}\text { Hispanic } \\
N=1,022\end{array}$ \\
\hline \multicolumn{4}{|l|}{ Outcome measure } \\
\hline Body mass index & $21.56(3.81)$ & $23.80^{\mathrm{a}}(5.57)$ & $22.43^{\mathrm{a}, \mathrm{b}}(4.56)$ \\
\hline \multicolumn{4}{|l|}{ Weight perceptions } \\
\hline Overperceived weight status & $24.90 \%$ & $14.10 \% \mathrm{a}^{\mathrm{a}}$ & $22.30 \%^{\mathrm{b}}$ \\
\hline Correct & $62.20 \%$ & $57.30 \%^{\mathrm{a}}$ & $61.80 \%{ }^{\mathrm{b}}$ \\
\hline Underperceived weight status & $12.90 \%$ & $28.60 \%{ }^{\mathrm{a}}$ & $15.90 \% \%^{\mathrm{a}, \mathrm{b}}$ \\
\hline \multicolumn{4}{|l|}{ Individual and household characteristics } \\
\hline Age & $15.78(1.82)$ & $15.81(1.85)$ & $15.70(1.94)$ \\
\hline Age of menarche & $12.22(1.51)$ & $11.64^{\mathrm{a}}(1.69)$ & $11.79^{\mathrm{a}, \mathrm{b}}(1.75)$ \\
\hline Youth income & $794.60(1,554)$ & $545.80^{\mathrm{a}}(1,176)$ & $592.60^{\mathrm{a}}(1,854)$ \\
\hline Hours per week worked by youth & $12.21(14.37)$ & $10.82^{\mathrm{a}}(14.95)$ & $10.19^{\mathrm{a}}(15.26)$ \\
\hline Youth lives with one biological parent & $21.00 \%$ & $50.40 \%{ }^{\mathrm{a}}$ & $30.10 \%{ }^{\mathrm{a}, \mathrm{b}}$ \\
\hline Mother does not work & $17.50 \%$ & $21.70 \%^{\mathrm{a}}$ & $26.70 \% \%^{\mathrm{a}, \mathrm{b}}$ \\
\hline Mother works part time & $20.40 \%$ & $11.90 \%^{\mathrm{a}}$ & $16.00 \% \%^{\mathrm{a}, \mathrm{b}}$ \\
\hline Mother works full time & $62.10 \%$ & $66.40 \%{ }^{\mathrm{a}}$ & $57.30 \% \%^{\mathrm{a}, \mathrm{b}}$ \\
\hline Urban residence & $70.61 \%$ & $76.96 \%^{\mathrm{a}}$ & $90.00 \% \%^{\mathrm{a}, \mathrm{b}}$ \\
\hline Suburban residence & $9.59 \%$ & $6.64 \% \%^{\mathrm{a}}$ & $4.51 \% \mathrm{o}^{\mathrm{a}}$ \\
\hline Rural residence & $19.80 \%$ & $16.40 \%{ }^{\mathrm{a}}$ & $5.49 \%$ a,b \\
\hline \multicolumn{4}{|l|}{ Parental socioeconomic status } \\
\hline Parental income (\$1982-1984) & $39,357(31,885)$ & $18,922^{\mathrm{a}}(25,479)$ & $21,450^{\mathrm{a}, \mathrm{b}}(28,114)$ \\
\hline Mother not completed high school & $8.70 \%$ & $18.20 \%^{\mathrm{a}}$ & $37.80 \% \%^{\mathrm{a}, \mathrm{b}}$ \\
\hline Mother completed high school & $35.90 \%$ & $42.50 \%{ }^{\mathrm{a}}$ & $34.40 \%{ }^{\mathrm{b}}$ \\
\hline Mother completed more than high school & $55.40 \%$ & $39.30 \%{ }^{\mathrm{a}}$ & $27.80 \% \%^{\mathrm{a}, \mathrm{b}}$ \\
\hline \multicolumn{4}{|l|}{$\begin{array}{l}\text { Neighborhood food, physical activity, and } \\
\text { socioeconomic contextual factors }\end{array}$} \\
\hline Price of fast food & $2.76(0.16)$ & $2.74^{\mathrm{a}}(0.20)$ & $2.84^{\mathrm{a}, \mathrm{b}}(0.20)$ \\
\hline Price of food at home & $1.09(0.10)$ & $1.09(0.12)$ & $1.14^{\mathrm{a}, \mathrm{b}}(0.17)$ \\
\hline Fast food restaurants (per 10,000 capita) & $2.36(0.82)$ & $2.60^{\mathrm{a}}(0.86)$ & $2.32^{\mathrm{b}}(0.63)$ \\
\hline Full-service restaurants (per 10,000 capita) & $10.54(2.93)$ & $11.34^{\mathrm{a}}(4.48)$ & $11.08^{\mathrm{a}}(3.25)$ \\
\hline Grocery stores (per 10,000 capita) & $3.00(1.44)$ & $4.14^{\mathrm{a}}(2.55)$ & $3.04^{\mathrm{b}}(1.78)$ \\
\hline Convenience stores (per 10,000 capita) & $1.96(1.14)$ & $2.48^{\mathrm{a}}(1.71)$ & $1.52^{\mathrm{a}, \mathrm{b}}(0.96)$ \\
\hline Physical activity outlets (per 10,000 capita) & $3.68(1.14)$ & $3.24^{\mathrm{a}}(1.47)$ & $2.97^{\mathrm{a}, \mathrm{b}}(1.20)$ \\
\hline County level median household income $(\$ 2000)$ & $44,194(10,417)$ & $39,209^{\mathrm{a}}(10,020)$ & $43,390^{\mathrm{b}}(12,001)$ \\
\hline
\end{tabular}

Summary statistics are weighted using the NLSY sampling weights.

$\mathrm{SD}$ is standard deviation.

${ }^{\text {a }}$ Statistically different than whites at $P \leq 0.05$; ${ }^{\text {b }}$ Statistically different from blacks at $P \leq 0.05$.

status. The results show a significant positive association between underperceived weight status and BMI for all races/ethnicities, and this association was found to be larger for black and Hispanic adolescents. White adolescent females who underperceived their weight status were estimated to have, on average, higher BMI by 1 unit when compared to white adolescents who correctly identified their weight status. Weight underperception by black and Hispanic adolescent females was associated with 3.8 and 2.2 higher BMI units, respectively, when compared to the corresponding adolescent females who correctly identified their weight status. Weight over-perceptions were not associated with BMI for any of the racial/ethnic subgroups.

\section{Discussion}

In this paper, we investigated racial/ethnic differences in weight misperceptions and their contribution towards racial/ethnic disparities in adolescent female BMI. Overall, more than one-half of female adolescents correctly identified their weight status, with statistically significantly more whites and Hispanics doing so compared to their black counterparts $(62.2 \%, 57.3 \%$, and $61.8 \%$ for white, black, and Hispanic adolescent females, resp.). On the one hand, white and Hispanic adolescent females were more likely to overperceive their weight status compared to black adolescent females, thinking they were heavier than they were clinically 
TABLE 2: Frequencies of weight perceptions by race and ethnicity and by weight categories.

\begin{tabular}{|c|c|c|c|c|c|c|c|c|c|}
\hline \multirow[b]{3}{*}{ (1) } & \multicolumn{3}{|c|}{ White } & \multicolumn{3}{|c|}{ Black } & \multicolumn{3}{|c|}{ Hispanic } \\
\hline & $\begin{array}{c}\text { Over } \\
\text { perceived } \\
\text { weight } \\
\text { status }\end{array}$ & $\begin{array}{c}\text { Correctly } \\
\text { perceived } \\
\text { weight } \\
\text { status }\end{array}$ & $\begin{array}{l}\text { Under } \\
\text { perceived } \\
\text { weight } \\
\text { status }\end{array}$ & $\begin{array}{c}\text { Over } \\
\text { perceived } \\
\text { weight } \\
\text { status }\end{array}$ & $\begin{array}{c}\text { Correctly } \\
\text { perceived } \\
\text { weight } \\
\text { status }\end{array}$ & $\begin{array}{c}\text { Under } \\
\text { perceived } \\
\text { weight } \\
\text { status }\end{array}$ & $\begin{array}{c}\text { Over } \\
\text { perceived } \\
\text { weight } \\
\text { status }\end{array}$ & $\begin{array}{c}\text { Correctly } \\
\text { perceived } \\
\text { weight } \\
\text { status }\end{array}$ & $\begin{array}{l}\text { Under } \\
\text { perceived } \\
\text { weight } \\
\text { status }\end{array}$ \\
\hline & (2) & (3) & (4) & (5) & (6) & (7) & (8) & (9) & (10) \\
\hline Underweight & $44.40 \%$ & $55.60 \%$ & - & $64.30 \%$ & $35.70 \%$ & - & $41.40 \%$ & $58.60 \%$ & - \\
\hline $\begin{array}{l}\text { Normal } \\
\text { Weight }\end{array}$ & $26.70 \%$ & $62.40 \%$ & $10.90 \%$ & $17.30 \% \%^{\mathrm{a}}$ & $68.00 \%^{\mathrm{a}}$ & $14.70 \% \%^{\mathrm{a}}$ & $24.70 \%{ }^{\mathrm{b}}$ & $64.30 \%$ & $11.00 \%{ }^{b}$ \\
\hline Overweight & $12.00 \%$ & $73.00 \%$ & $15.00 \%$ & $8.50 \%$ & $46.60 \%^{\mathrm{a}}$ & $44.90 \%{ }^{\mathrm{a}}$ & $16.50 \%{ }^{b}$ & $62.50 \%{ }^{\mathrm{a}, \mathrm{b}}$ & $21.00 \%{ }^{\mathrm{b}}$ \\
\hline Obese & - & $41.00 \%$ & $59.00 \%$ & - & $27.30 \%^{\mathrm{a}}$ & $72.70 \%^{\mathrm{a}}$ & - & $38.70 \%$ & $61.30 \%$ \\
\hline $\mathrm{N}$ & 655 & 1652 & 345 & 183 & 739 & 367 & 222 & 623 & 159 \\
\hline
\end{tabular}

Summary statistics are weighted using the NLSY sampling weights.

a Statistically different from whites at $P \leq 0.05$; ${ }^{\text {b }}$ Statistically different from blacks at $P \leq 0.05$.

Underweight: BMI percentile $<5$; normal weight: $85>$ BMI percentile $\geq 5$; overweight: $95>$ BMI percentile $\geq 85$; obese: BMI percentile $\geq 95$.

TABle 3: Percentage contributions from decomposition model of racial and ethnic disparities in adolescent body mass index.

\begin{tabular}{|c|c|c|c|c|}
\hline \multirow[b]{2}{*}{ (Column) } & \multicolumn{2}{|c|}{$\begin{array}{c}\text { Black-white adolescent females } \\
\qquad \begin{array}{c}\text { (BMI gap }=2.2 \text { units }) \\
N=4013\end{array}\end{array}$} & \multicolumn{2}{|c|}{$\begin{array}{c}\text { Hispanic-white adolescent females } \\
(\text { BMI gap }=0.9 \text { units }) \\
N=3719\end{array}$} \\
\hline & (1) & (2) & (3) & (4) \\
\hline Variables & Model 1 & Model 2 & Model 1 & Model 2 \\
\hline $\begin{array}{l}\text { Individual, parental, and } \\
\text { economic contextual } \\
\text { factors }\end{array}$ & $44.72 \%$ & $41.36 \%$ & $62.81 \%$ & $59.83 \%$ \\
\hline Weight misperceptions & & $12.96 \%$ & & $3.31 \%$ \\
\hline Total percentage explained & $44.72 \%$ & $54.32 \%$ & $62.81 \%$ & $63.13 \%$ \\
\hline
\end{tabular}

Variables included in each category correspond to the list shown in Table 1.

(24.9\%, $14.1 \%$, and $22.3 \%$ for white, black, and Hispanic adolescent females, resp.). On the other hand, compared to white adolescent females, more than twice as many black adolescents and close to one quarter more Hispanic adolescents underperceived their weight status, thinking they were lighter than they were clinically $(12.9 \%, 28.6 \%$, and $15.9 \%$ for white, black, and Hispanic adolescent females, resp.). In particular, almost three times more overweight black adolescents and 40\% more overweight Hispanic adolescents underperceived their weight status when compared to their overweight white counterparts. In addition, $23 \%$ more obese black adolescents underperceived their weight status when compared to their obese white counterparts.

We found that weight misperceptions were particularly important factors in explaining the black-white BMI gap for adolescent girls, increasing the total explained portion of the BMI disparity from $44.7 \%$ to $54.3 \%$. When added to the Hispanic-white BMI model, weight misperceptions increased the total explained portion of the BMI disparity just slightly from $62.8 \%$ to $63.1 \%$. Weight misperceptions explained $13.0 \%$ and $3.3 \%$ of the black-white and Hispanicwhite BMI gaps, respectively. The large increase in the total explained portion of the black-white BMI gap from the inclusion of weight misperceptions (from $44.7 \%$ to $54.3 \%$, an approximate 10 percentage points increase) was close to the same size as the explained portion attributable to the weight misperception variables (13.3\%), which suggests that previously omitted weight misperceptions are important determinants of the black-white racial disparity in adolescent female BMI that were not accounted for by the individual, household, and contextual controls.

In addition, weight underperceptions were significantly associated with higher BMI for all adolescent girls but to a greater extent for black and Hispanic adolescents. This suggests that not only do the differences in misperceptions contribute to the explained racial/ethnic BMI gaps, but the differential association of underperceptions with BMI further exacerbates the unexplained part of the disparity.

This paper is subject to a number of limitations. First, height and weight were self-reported. Second, the ACCRA price data had a number of limitations, which included: the data were only collected in a limited number of cities and metropolitan areas; the data were based on establishment samples that reflect a higher standard of living; and ACCRA did not always sample the same cities continuously and hence the data were not fully comparable over time [45] Third, the outlet density count measures were subject to count error and we were limited to using SIC codes which may have classification errors [46]. Fourth, the geographic identifiers in the NLSY97 data only allowed us to control for 
TABLE 4: Regressions estimates of adolescents body mass index, regression coefficients (SE).

\begin{tabular}{|c|c|c|c|}
\hline Variables & White & Black & Hispanic \\
\hline \multirow[t]{2}{*}{ Overperceived weight status } & 0.22 & $-0.57^{b}$ & 0.44 \\
\hline & $(0.16)$ & $(0.42)$ & $(0.29)$ \\
\hline \multirow[t]{2}{*}{ Underperceived weight status } & $0.96^{* * *}$ & $3.75^{* * * a}$ & $2.21^{* * * \mathrm{~b}}$ \\
\hline & $(0.34)$ & $(0.52)$ & $(0.70)$ \\
\hline$N$ & 2,697 & 1,316 & 1,022 \\
\hline
\end{tabular}

${ }^{*}$ Significant at $P \leq 0.10 ;{ }^{* *}$ Significant at $P \leq 0.05 ;{ }^{* *}$ Significant at $P \leq 0.01$.

$\mathrm{SE}$ is standard error.

All regressions control for individual and household characteristics, parental socioeconomic status, and neighborhood food, physical activity, and socioeconomic contextual factors.

${ }^{a}$ Estimate is statistically significantly different to the estimate for whites at $P \leq 0.05$.

${ }^{\mathrm{b}}$ Estimate is statistically significantly different to the estimate for whites at $P \leq 0.10$.

the economic contextual measures at the county level rather than at more proximate levels. Fifth, smaller sample sizes among the gender-racial/ethnic subgroups may have limited statistical power in our regression analyses that assessed the differential associations with BMI by race and ethnicity. Finally, differences in other social and cultural factors such as immigration generation to the USA, social support, and stress, as well as dietary and physical activity preferences may contribute to the racial/ethnic disparities and deserve further attention in future disparities-related obesity research.

Despite these limitations, several key and interesting results emerged from our analyses. We documented that compared to white adolescents, higher percentages of black and Hispanic adolescent females underperceived their weight status. This disparity was particularly prevalent between black and white overweight adolescent females. These study findings are consistent with a recent study where black and Hispanic adults reported self-perceived health status as higher than their actual clinical health status [47]. Positive attitudes toward health and weight, in particular, among black and Hispanic adults may have a protective effect against certain eating disorders such as anorexia nervosa [23]. At the same time, however, these perceptions may pose a serious problem with respect to increased risk of obesity.

In addition, our estimation results showed that weight underperceptions were significantly associated with adolescent female BMI for all three racial/ethnic groups, particularly for black and Hispanic adolescents for which the estimated association was higher than for whites. These results, although compelling, document only the association between weight underperceptions and female adolescents BMI. Further research is needed to clearly establish potential causality.

Overall, the study results suggest that policies aimed at reducing the obesity epidemic and the racial/ethnic BMI gap should try to address the racial/ethnic differences in weight misperceptions through early education regarding the interpretation and identification of one's weight status. Adjustments in perceptions may help to reduce disparities in weight outcomes, particularly between black and white adolescent females, and help to reduce related health disparities. Given that weight misperceptions are formed at the individual level but are often influenced by cultural norms, there may be an important role for school-based identification of clinical overweight and obesity status to help reduce the incidence of obesity among adolescent females.

\section{Acknowledgments}

Support for this research was provided by the National Institute of Diabetes and Digestive and Kidney Diseases, National Institutes of Health (R01DK81335-01A1), and the Robert Wood Johnson Foundation Bridging the Gap ImpacTeen project. The views expressed herein are solely those of the authors and do not reflect the official views or positions of the National Institutes of Health or the Robert Wood Johnson Foundation.

\section{References}

[1] C. L. Ogden and M. D. Carroll, "Prevalence of Overweight, Obesity, and Extreme Obesity Among Adults: United States, Trends 1960-1962 Through 2007-2008," NCHS-Health EStats, 2010.

[2] C. L. Ogden, M. D. Carroll, L. R. Curtin, M. M. Lamb, and K. M. Flegal, "Prevalence of high body mass index in US children and adolescents, 2007-2008," Journal of the American Medical Association, vol. 303, no. 3, pp. 242-249, 2010.

[3] D. S. Freedman, L. K. Khan, M. K. Serdula, W. H. Dietz, S. R. Srinivasan, and G. S. Berenson, "The relation of childhood BMI to adult adiposity: the Bogalusa heart study," Pediatrics, vol. 115, no. 1, pp. 22-27, 2005.

[4] USDHHS, The Surgeon General's Call to Action to Prevent and Decrease Overweight and Obesity, Rockville USDHHS, 2001.

[5] E. Han, E. C. Norton, and S. C. Stearns, "Weight and wages: fat versus lean paychecks," Health Economics, vol. 18, no. 5, pp. 535-548, 2009.

[6] E. Han, E. C. Norton, and L. M. Powell, "Direct and indirect effects of body weight on adult wages," Economics and Human Biology, vol. 9, no. 4, pp. 381-392, 2011.

[7] P. Gordon-Larsen, L. S. Adair, and B. M. Popkin, "The relationship of ethnicity, socioeconomic factors, and overweight in U.S. adolescents," Obesity Research, vol. 11, no. 1, pp. 121129, 2003.

[8] Y. Wang and Q. Zhang, "Are American children and adolescents of low socioeconomic status at increased risk of obesity? Changes in the association between overweight and family 
income between 1971 and 2002," American Journal of Clinical Nutrition, vol. 84, no. 4, pp. 707-716, 2006.

[9] L. M. Powell, R. Wada, R. C. Krauss, and Y. Wang, "Ethnic disparities in adolescent body mass index in the United States: the role of parental socioeconomic status and economic contextual factors," Social Science and Medicine, 2012.

[10] W. L. Johnson-Taylor, R. A. Fisher, V. S. Hubbard, P. StarkeReed, and P. S. Eggers, "The change in weight perception of weight status among the overweight: comparison of NHANES III (1988-1994) and 1999-2004 NHANES," International Journal of Behavioral Nutrition and Physical Activity, vol. 5, article 9, 2008.

[11] M. A. Burke, F. W. Heiland, and C. M. Nadler, "From overweight to about right: evidence of a generational shift in body weight norms," Obesity, vol. 18, no. 6, pp. 1226-1234, 2010.

[12] V. Salcedo, J. L. Gutierrez-Fisac, P. Guallar-Castillon, and F. Rodriguez-Artalejo, "Trends in overweight and misperceived overweight in Spain from 1987 to 2007," International Journal of Obesity, vol. 34, no. 12, pp. 1759-1765, 2010.

[13] S. Paeratakul, M. A. White, D. A. Williamson, D. H. Ryan, and G. A. Bray, "Sex, race/ethnicity, socioeconomic status, and BMI in relation to self-perception of overweight," Obesity Research, vol. 10, no. 5, pp. 345-350, 2002.

[14] K. J. Flynn and M. Fitzgibbon, "Body images and obesity risk among black females: a review of the literature," Annals of Behavioral Medicine, vol. 20, no. 1, pp. 13-24, 1998.

[15] C. A. Vaughan, W. P. Sacco, and J. W. Beckstead, "Racial/ethnic differences in Body Mass Index: the roles of beliefs about thinness and dietary restriction," Body Image, vol. 5, no. 3, pp. 291-298, 2008.

[16] C. S. Barroso, R. J. Peters, R. J. Johnson, S. H. Kelder, and T. Jefferson, "Beliefs and perceived norms concerning body image among African-American and latino teenagers," Journal of Health Psychology, vol. 15, no. 6, pp. 858-870, 2010.

[17] S. H. Thompson, R. G. Sargent, and K. A. Kemper, "Black and white adolescent males' perceptions of ideal body size," Sex Roles, vol. 34, no. 5-6, pp. 391-406, 1996.

[18] S. Parker, M. Nichter, M. Nichter, N. Vuckovic, C. Sims, and C. Ritenbaugh, "Body image and weight concerns among African Americans and white adolescent females: differences that make a difference," Human Organization, vol. 54, no. 2, pp. 103-114, 1995.

[19] P. B. Schuler, D. Vinci, R. M. Isosaari et al., "Body-shape perceptions and body mass index of older African American and European American women," Journal of Cross-Cultural Gerontology, vol. 23, no. 3, pp. 255-264, 2008.

[20] R. R. Dorsey, M. S. Eberhardt, and C. L. Ogden, "Racial/ethnic differences in weight perception," Obesity, vol. 17, no. 4, pp. 790-795, 2009.

[21] F. Kuchler and J. N. Variyam, "Mistakes were made: misperception as a barrier to reducing overweight," International Journal of Obesity, vol. 27, no. 7, pp. 856-861, 2003.

[22] E. Stice, "Review of the evidence for a sociocultural model of bulimia nervosa and an exploration of the mechanisms of action," Clinical Psychology Review, vol. 14, no. 7, pp. 633-661, 1994.

[23] C. S. Warren, D. H. Gleaves, A. Cepeda-Benito, M. D. C. Fernandez, and S. Rodriguez-Ruiz, "Ethnicity as a protective factor against internalization of a thin ideal and body dissatisfaction," International Journal of Eating Disorders, vol. 37, no. 3, pp. 241-249, 2005.
[24] M. Alegria, M. Woo, Z. Cao, M. Torres, X. L. Meng, and R. Striegel-Moore, "Prevalence and correlates of eating disorders in Latinos in the United States," International Journal of Eating Disorders, vol. 40, supplement 3, pp. S15-S21, 2007.

[25] R. Chamorro and Y. Flores-Ortiz, "Acculturation and disordered eating patterns among Mexican American women," International Journal of Eating Disorders, vol. 28, no. 1, pp. 125-129, 2000.

[26] A. D. Powell and A. S. Kahn, "Racial differences in women's desires to be thin," International Journal of Eating Disorders, vol. 17, no. 2, pp. 191-195, 1995.

[27] S. Kumanyika, J. F. Wilson, and M. Guilford-Davenport, "Weight-related attitudes and behaviors of black women," Journal of the American Dietetic Association, vol. 93, no. 4, pp. 416-422, 1993.

[28] N. Wolf, The Beauty Myth: How Images of Beauty Are Used against Women, William Morrow and Company, New York, NY, USA, 1991.

[29] M. A. Poran, "Denying diversity: perceptions of beauty and social comparison processes among Latina, Black, and White women," Sex Roles, vol. 47, no. 1-2, pp. 65-81, 2002.

[30] K. J. Miller, D. H. Gleaves, T. G. Hirsch, B. A. Green, A. C. Snow, and C. C. Corbett, "Comparisons of body image dimensions by race/ethnicity and gender in a university population," International Journal of Eating Disorders, vol. 27, no. 3, pp. 310-316, 2000.

[31] A. Roberts, T. F. Cash, A. Feingold, and B. T. Johnson, "Are black-white differences in females' body dissatisfaction decreasing? A meta-analytic review," Journal of Consulting and Clinical Psychology, vol. 74, no. 6, pp. 1121-1131, 2006.

[32] P. C. Chandler-Laney, G. R. Hunter, N. C. Bush et al., "Associations among body size dissatisfaction, perceived dietary control, and diet history in African American and European American women," Eating Behaviors, vol. 10, no. 4, pp. 202208, 2009.

[33] A. M. Kelly, M. Wall, M. E. Eisenberg, M. Story, and D. Neumark-Sztainer, "Adolescent girls with high body satisfaction: who are they and what can they teach us?" Journal of Adolescent Health, vol. 37, no. 5, pp. 391-396, 2005.

[34] L. W. Kronenfeld, L. Reba-Harrelson, A. von Holle, M. L. Reyes, and C. M. Bulik, "Ethnic and racial differences in body size perception and satisfaction," Body Image, vol. 7, no. 2, pp. 131-136, 2010.

[35] C. E. Rucker and T. F. Cash, "Body images, body-size perceptions, and eating behaviors among African-American and white college women," Int J Eat Disord, vol. 12, no. 3, pp. 291-299, 1992.

[36] M. L. Fitzgibbon, L. R. Blackman, and M. E. Avellone, "The relationship between body image discrepancy and body mass index across ethnic groups," Obesity Research, vol. 8, no. 8, pp. 582-589, 2000.

[37] L. M. Powell, "Fast food costs and adolescent body mass index: evidence from panel data," Journal of Health Economics, vol. 28, no. 5, pp. 963-970, 2009.

[38] A. S. Blinder, "Wage discrimination: reduced form and structural estimates," The Journal of Human Resources, vol. 8, no. 4, pp. 436-455, 1973.

[39] R. Oaxaca, "Male-female wage differentials in Urban labor markets," International Economic Review, vol. 14, no. 3, pp. 693-709, 1973.

[40] D. Neumark, "Employers' discriminatory behavior and the estimation of wage discrimination," The Journal of Human Resources, vol. 23, no. 3, pp. 279-295, 1988. 
[41] W. Chung, S. Lim, and S. Lee, "Factors influencing gender differences in smoking and their separate contributions: evidence from South Korea," Social Science and Medicine, vol. 70, no. 12, pp. 1966-1973, 2010.

[42] M. C. Auld and L. M. Powell, "The economics of obesity: research and policy implications for a Canada-US comparison," in Health Services Restructuring in Canada: New Evidence and New Directions, C. M. Beach, R. P. Chaykowski, S. Shortt, F. St-Hilaire, and A. Sweetman, Eds., pp. 305-333, ohn Deutsch Institute for the Study of Economic Policy, Ontario, Canada, 2006.

[43] J. C. Font, D. Fabbri, and J. Gil, "Decomposing cross-country differences in levels of obesity and overweight: does the social environment matter?" Social Science and Medicine, vol. 70, no. 8, pp. 1185-1193, 2010.

[44] A. Colin Cameron, J. B. Gelbach, and D. L. Miller, "Robust inference with multiway clustering," Journal of Business and Economic Statistics, vol. 29, no. 2, pp. 238-249, 2011.

[45] L. M. Powell and F. J. Chaloupka, "Food prices and obesity: evidence and policy implications for taxes and subsidies," Milbank Quarterly, vol. 87, no. 1, pp. 229-257, 2009.

[46] L. M. Powell, E. Han, S. N. Zenk et al., "Field validation of secondary commercial data sources on the retail food outlet environment in the U.S," Health and Place, vol. 17, no. 5, pp. 1122-1131, 2011.

[47] M. Perez and C. S. Warren, "The relationship between quality of life, binge-eating disorder, and obesity status in an ethnically diverse sample," Obesity, vol. 20, no. 4, pp. 879-885, 2012. 


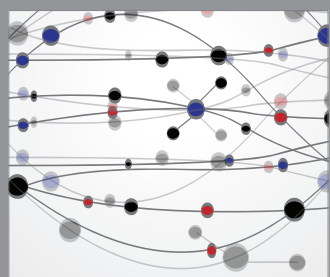

The Scientific World Journal
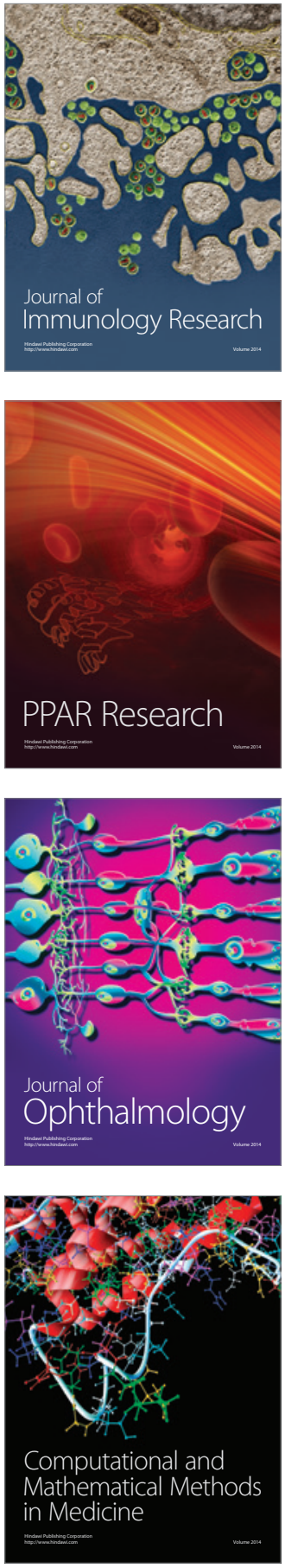

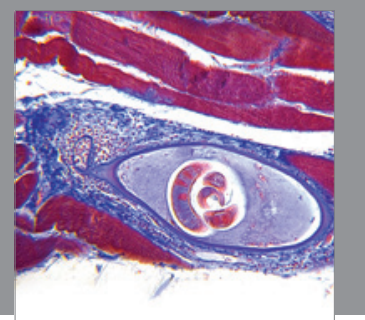

Gastroenterology

Research and Practice
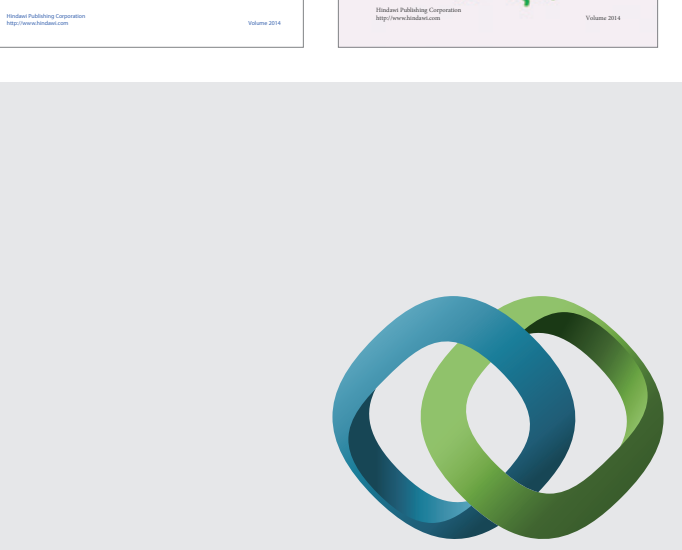

\section{Hindawi}

Submit your manuscripts at

http://www.hindawi.com
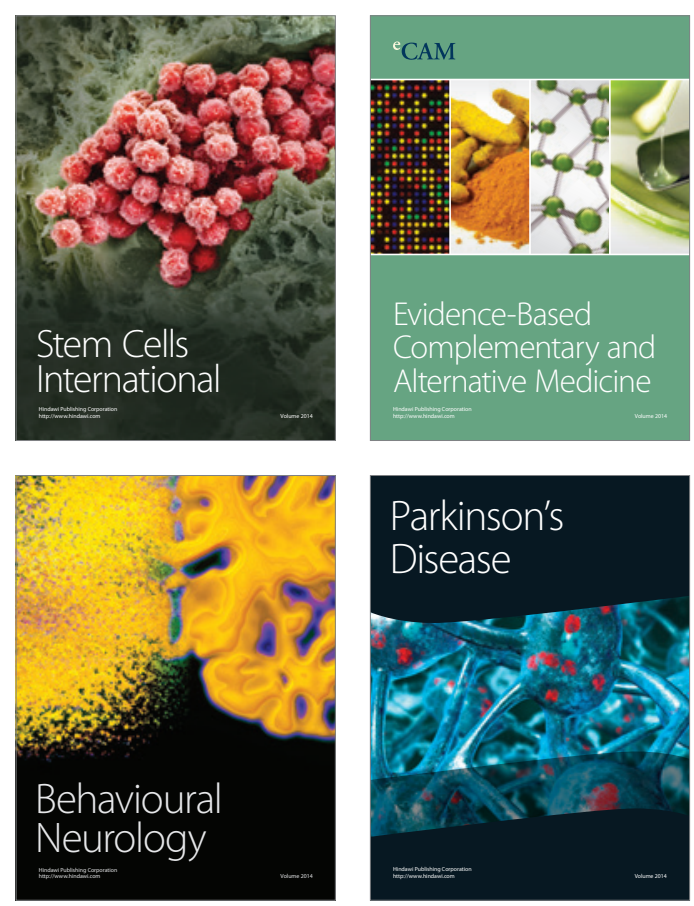

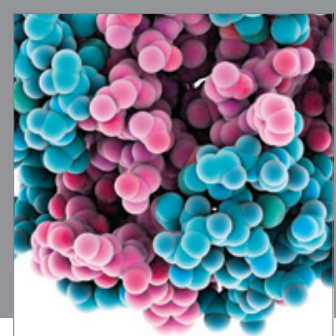

Journal of
Diabetes Research

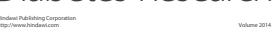

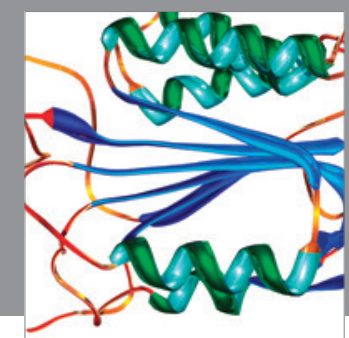

Disease Markers
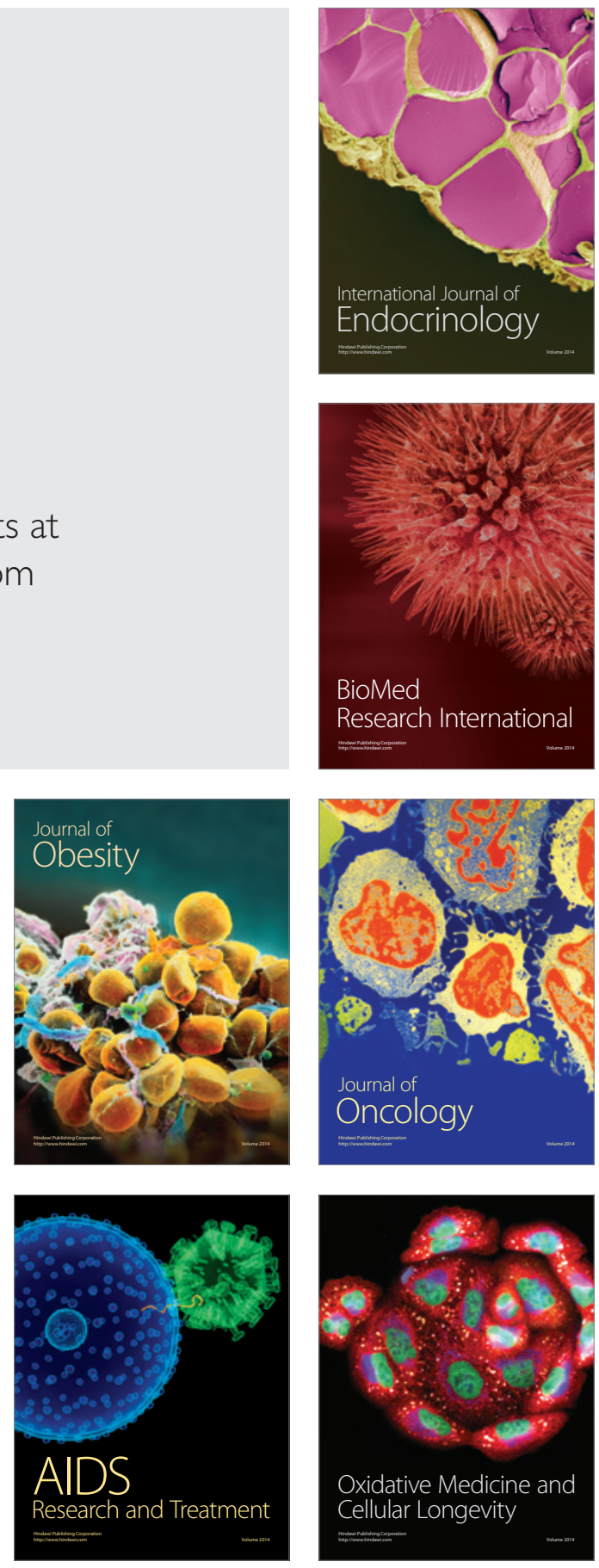